\title{
Estimating the Impact of School Education on Contraception Use among Adolescents Aged 15-19 in Burkina Faso and Nigeria: Evidence from a Heckman Two-Step Correction Model
}

\author{
Miaba Louise Lompo ${ }^{1}$, Jean-Louis Bago ${ }^{2} \&$ Wamadini dite Minata Souratié ${ }^{3}$ \\ ${ }^{1}$ Department of Information and Communication, Laval University, Canada \\ ${ }^{2}$ Department of Economics, Laval University, Canada \\ ${ }^{3}$ Unit of Training and Research in Economics and Management, University of Ouaga II, Burkina Faso \\ Correspondence: Jean-Louis Bago, Department of Economics, Laval University, Canada.
}

Received: May 23, 2018

Accepted: June 11, 2018 Online Published: June 18, 2018

doi:10.5539/jel.v7n5p31

URL: https://doi.org/10.5539/jel.v7n5p31

\begin{abstract}
Sexually Transmitted Infections (STIs) still raise serious concerns for adolescents' sexual health in west-African developing countries. To this extent, promoting contraception use among sexually active adolescents is a major key to addressing this problem. Yet, the rate of contraception use by adolescents remains surprisingly low in these countries. Using the Demographic Health Survey of Burkina Faso (2014) and Nigeria (2013), this paper examines the influence of school education on contraception use among sexually active male and female adolescents aged 15-19 in Burkina Faso and Nigeria. The standard estimates using Probit regressions suggest that achieving a primary school education increases the probability of a sexually active adolescent to use contraception by 8.26 percentage points (Burkina Faso) and 17.2 percentage points (Nigeria). This effect increases to 20.3 percentage points (Burkina Faso) and 34.7 percentage points (Nigeria) for adolescents with a secondary or higher school education. However, these baseline estimates are biased because adolescents' decision to engage into sexual activity is not random. In light of this, a Heckman Correction Model (HCM) has been applied to account for this selection bias. The results show that the Probit regressions underestimate the effect of education on adolescents' likelihood to use contraception in Burkina Faso and overestimate this effect in Nigeria. In fact, compared to adolescents with no school education, HCM estimates show that adolescents with primary and secondary (or higher) school education have respectively 10.2 and 24.4 percentage points more in the use of contraception in Burkina Faso and 15.1 and 34 percentage points in Nigeria. Together, these results suggest that the exposure to school education increases contraception use among the adolescents in both Burkina Faso and Nigeria.
\end{abstract}

Keywords: school education, contraception, adolescent, Heckman Correction Model, sexually transmitted infections

\section{Introduction}

Despite the great popularization of contraceptive methods, the rate of Sexually Transmitted Infections (STIs) in developing countries remains high among male and female adolescents (Morris \& Rushwan, 2015). In fact, the statistics on sexual health indicate that up to $37 \%$ of all new HIV infections in Sub-Saharan African countries are among adolescents aged 15-24 (UN, 2016). As an explanation to this fact, Dehne, Riedner, Berer, and Organization (2005) shows that adolescents are less likely to use contraception than adults. Analysing the increase of sexual activities among adolescents in Nigeria, Alabi and Oni (2017) argues that the promotion of contraception use among adolescents is one of the most important public health challenges. In a similar study, Biddlecom, Singh, and Munthali (2007) also finds that the contraceptive methods are still underutilized in Burkina Faso.

In the literature, several studies analysed the determinants of adolescents' contraception use, focusing on the access to efficient contraceptive methods (Arcidiacono, Khwaja, \& Ouyang, 2012; DiCenso, Guyatt, Willan, \& Griffith, 2002; Klick \& Stratmann, 2008) and sex education (Cannonier, 2012; Girma \& Paton, 2014; Kohler, Manhart, \& Lafferty, 2008; Oettinger, 1999; Sabia, 2006; Santelli, Lindberg, Finer, \& Singh; Winner et al., 2012) as the main determinants of contraception use. Another set of literature focuses on socio-economic and 
demographic factors such as the less widespread family planning behavior (Khan, Mishra, Arnold, \& Abderrahim, 2007) and the higher fertility preferences (Bongaarts, 2003) as the explanation of the low rate of contraception use in developing countries. Yet, since the last decade, policies promoting family planning in developing countries fail to increase contraception use (Cleland, Ndugwa, \& Zulu, 2011).

On the other hand, the effect of education attainment as a key determinant of contraception use is less explored in developing countries although a large body of literature suggests that contraceptive use is strongly associated with schooling (Ainsworth, Beegle, \& Nyamete, 1996; Beekle \& McCabe, 2006; Hogan, Berhanu, \& Hailemariam, 1999; Korra, 2002). A recent study by Larsson and Stanfors (2014) shows that the low education attainment in developing countries is an important barrier to understand the importance and all the benefits of contraception use. Using the demographic health surveys of four developing countries ( Ghana, Kenya, Madagascar and Zambia), Larsson and Stanfors (2014) finds a positive relationship between women's education and contraception use. Their sampling method excluded women who had not been sexually active. However, by limiting the sample to sexually active women, their results are likely to suffer from selection bias since being sexually active is not random. Heckman (1979) shows that a sample selection bias arises when the sample of study is not random. In our context, the decision to use or not to use contraception is observed only for adolescents who are actually engaged in sexual activities but the decision to enter in sexual activity is not random (Rashad \& Kaestner, 2004). This decision depends on a set of personal and social behaviors such as alcohol consumption, smoking and many other factors which are unmeasured (Rashad \& Kaestner, 2004). This sample selection causes the standard estimates (probit, logit, linear probability model) to be inconsistent. To access the true causal effect on education on contraception use, a HCM is applied to account for this selection issue. To the best of our knowledge, this is the first paper, to account for the sample selection in estimating the effect of education on contraception use in developing countries.

This article is based on data from a low-income country (Burkina Faso) and middle-income country (Nigeria) to account for the level of economic development. In fact, Nigeria was ranked as the most developed country in Africa according to the Gross Domestic Product (GDP-2017) while Burkina Faso was ranked as one of the poorest (World Bank, 2017). In addition, the youth literacy rate was estimated at 21.6\% in 2013 in Burkina Faso and 66.38 in Nigeria (World Bank, 2014). Interestingly, the statistics in our data reveals that the level of contraception use among adolescents aged $15-19$ in Nigeria is $38.4 \%$ while it is $26 \%$ in Burkina Faso, which represents a huge difference of $12 \%$ percentage points.

In this empirical analysis, Demographic Health Surveys of Burkina Faso (2014) and Nigeria (2013) are used to examine the influence of school education on contraception use among the sexually active adolescents aged 15-19. The study focuses on both male and female adolescents. The estimation strategy comprises two main steps. First, the effect of education is estimated using a standard Probit model. Second, to access a consistent estimate of the effect of education on contraception use, a HCM is applied to account for the sample selection.

In the case of Burkina Faso, the baseline results suggest that having a primary education increases the adolescents' probability of using contraception during intercourse by 8.26 percentage points compared to adolescents without education at all. This effect increases to 20.3 percentage points for adolescents with a secondary education or more. In the case of Nigeria, the effect of education on contraception use is also positive and statistically significant. The extent of this effect is larger in Nigeria compared to Burkina Faso. In fact, the probability that an adolescent with a primary school education will use contraception is 17.2 percentage points higher than the probability of an adolescent who has not school education. It is also observed that having a secondary school education or tertiary education increases the probability that an adolescent will use contraception by 34.7 percentage points. Hence, these results confirm that education has a positive effect on contraception use in Burkina Faso and Nigeria. However, a potential drawback of this standard Probit approach is that it may yield inconsistent estimates because of the selection of an adolescent in sexual activity.

The consistent results from the HCM show that the Probit estimates are biased. In Burkina Faso, the results suggest that having a basic education increased the probability to use contraception by 10.5 percentage point which is higher than the Probit estimates. The effect of secondary education is also higher (24.4 percentage points) than the Probit estimates. In Nigeria, having a primary education increase the probability of using contraception by 15.1 percentage point which smaller than the standard Probit estimates. The HCM estimated effect of secondary and higher education stood at 34 percentage points which is also smaller than the effect estimated in baseline Probit.

The rest of this paper is structured as follows. Section 2 presents the data and identification strategy, Section 3 presents the descriptive statistics and Section 4 presents the estimation results. Section 5 discusses the results 
and Section 6 provides a conclusion to the paper.

\section{Data and Identification Strategy}

\subsection{Data}

This article is based on data from Demographic and Health Surveys of Burkina Faso (2014) and Nigeria (2013). It examines the effect of male and female adolescents' education on the likelihood that she/he uses contraception during intercourse. This database contains information about participants' age, level of education, gender, sexual activity, age at first sex, number of sexual partners, exposure to media, access to information about STIs and contraception use. Education is defined as a categorial variable equals 0 if the adolescent reported that he has never been at school, 1 if he has a primary school education and 2 if he has a secondary or higher school education. The dependent variable of interest for contraception use was built using the questionnaire for instance, the respondents were asked about various contraceptive method used. Subsequently, the contraception use is defined as a dummy variable equals 1 if the adolescent reported that he/she uses a contraceptive method during sex and 0 otherwise. The data were restricted to individuals aged between 15 and 19 years old. Our main sample contains 1722 adolescents in Burkina Faso and 3983 adolescents in Nigeria.

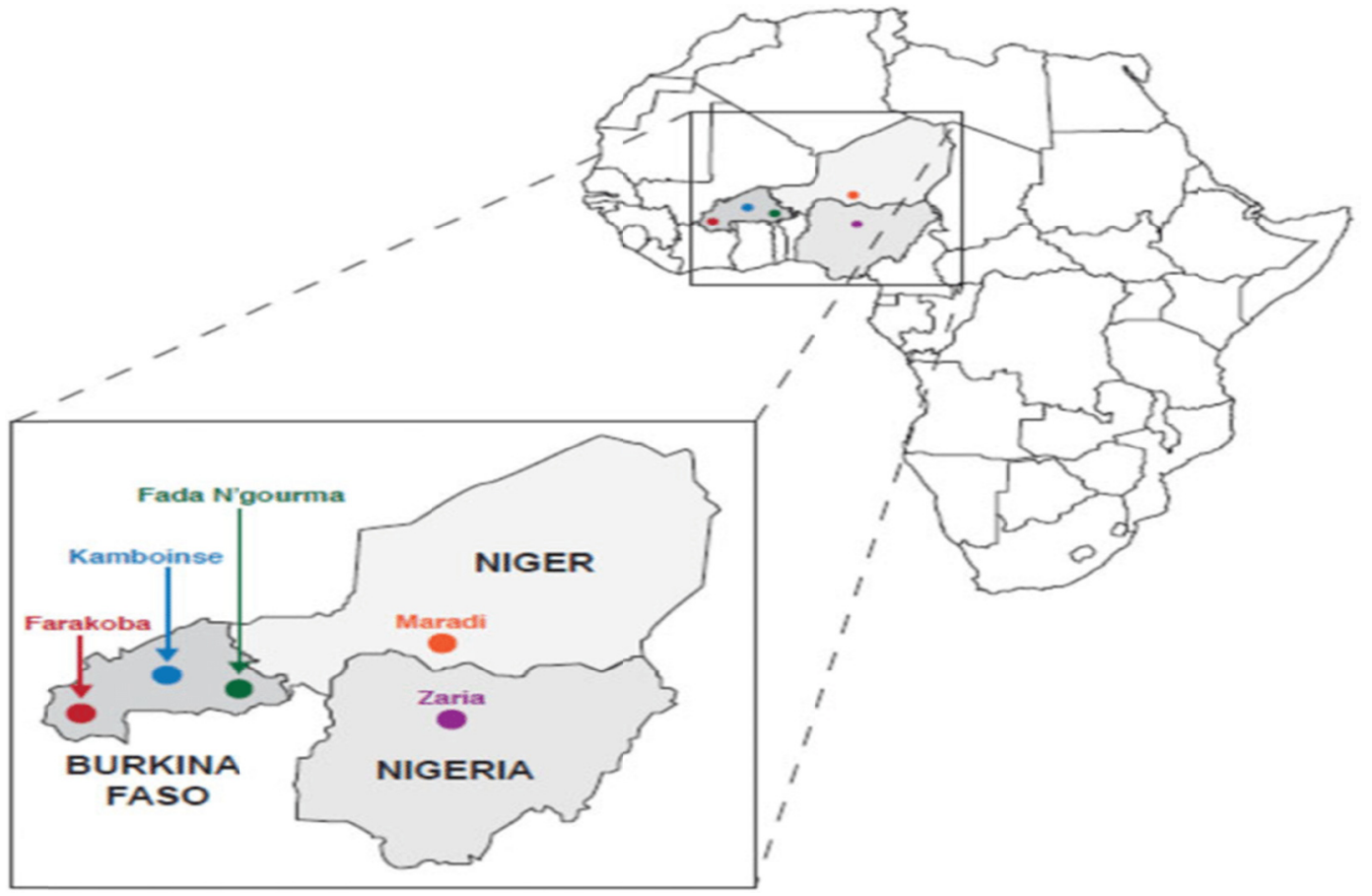

Figure 1. Maps showing location of Nigeria and Burkina Faso

\subsection{Identification Strategy}

This paper uses two identification methods to estimate the effect of an adolescent's education on the likelihood that she is using contraception or not. First, the baseline strategy uses standard Probit regression. Then, the HCM for sample selection approach is estimated as a second identification strategy.

\subsubsection{Baseline Strategy}

Our primary interest is to estimate a standard Probit model. Let $i$ denotes a sexually active adolescent characterized by a level of Education $E d u_{i}$ and a vector of other characteristics $X_{i}$. $X_{i}$ includes age, gender, age at first sex, number of sexual partners, exposure to media, access to information about STIs and the adolescent's area of residence.

$Y_{i}$ denotes the decision about contraception use (equals 1 if he/she uses contraception and 0 otherwise). The decision can be written as follows:

$$
Y_{i}=\left\{\begin{array}{l}
1 \quad \text { if } Y_{i}^{*}=\alpha_{0}+\sum_{j=1}^{2} \alpha_{j 1} E d u_{j i}+X_{i}^{\prime} \beta+\varepsilon>0 \quad \text { (Contraception use) } \\
0 \quad \text { if } Y_{i}^{*}=\alpha_{0}+\sum_{j=1}^{2} \alpha_{j 1} E d u_{j i}+X_{i}^{\prime} \beta+\varepsilon<0 \quad \text { (No contraception use) }
\end{array}\right.
$$


where $Y_{i}^{*}$ is the latent variable whose sign determines whether to use or not to use contraception and $\varepsilon$ is a zero-mean error term. $\beta$ captures the parameters of covariates that affect the decision that adolescents will use contraception.

The probability that contraception is used can then be written as follows:

$$
\begin{aligned}
P\left(Y_{i}=1 \mid X_{i}\right) & =P\left(Y_{i}^{*}>0\right) \\
& =P\left(\alpha_{0}+\sum_{j=1}^{2} \alpha_{j} E d u_{j i}+X_{i}^{\prime} \beta>0\right) \\
& =P\left(\varepsilon<\alpha_{0}+\sum_{j=1}^{2} \alpha_{j} E d u_{j i}+X_{i}^{\prime} \beta\right) \\
& =\Phi\left(\alpha_{0}+\sum_{j=1}^{2} \alpha_{j} E d u_{j i}+X_{i}^{\prime} \beta\right)
\end{aligned}
$$

Where $\Phi(\cdot)$ is the normal distribution. This probability and the parameters of the model are estimated using a maximum likelihood. To deal with the potential clustering of observations at the neighbourhood level, the model is estimated using heteroskedasticity robust standard errors. In order to conduct the interpretations, the marginal effect of each variable on the probability of using contraception are estimated.

However, baseline estimates of Equation (1) are subjected to bias due to selection bias. Indeed, the behavior about contraception of adolescents who are actually engaged in sexual activity is observed. Rashad and Kaestner (2004) shows that the decision to enter in sexual activity is not random and depends on a set of personal and social behaviors such as alcohol consumption and many others which are unmeasured. In a similar analysis, Evans, Oates, and Schwab (1992) shows that peer group influence also affects adolescents' sex behavior. In this context, the standard Probit estimates become subject to sample selection bias. This paper uses a HCM to account for this selection issue.

\subsubsection{Heckman Correction Model}

As suggested in the previous section, the main challenge in identifying the effect of education on the decision to use contraception or not is the presence of potential sample selection issues. Let $S_{i}$ denotes the selection variable and equals 1 if an adolescent is engaged in sexual activity and 0 otherwise. In our paradigm, the HCM (Gronau, 1974; Heckman, 1979; Lewis, 1974) assumes that there exists an underlying regression relationship between education and contraception use following Equation (1). However, the sample selection bias arises because the decision to use contraception (or not) is observed only when an adolescent is engaged in sexual activity $\left(S_{i}=1\right)$. In fact, this decision is not observed for an adolescent who has never engaged in sexual activity $\left(S_{i}=0\right)$. Given that the decision of adolescents to engage into sexual activity is not random, adolescents who are engaged in sexual activity might share some common characteristics. In such case, the standard Probit estimates are likely to be biased.

The HCM estimation includes the analysis of the following selection equation:

$$
S_{i}= \begin{cases}1 & \text { if } S_{i}^{*}=Z_{i}^{\prime} \pi+\mu>0 \quad \text { (Sexually active) } \\ 0 & \text { if } S_{i}^{*}=Z_{i}^{\prime} \pi+\mu<0 \text { (Not sexually active) }\end{cases}
$$

where $Z_{\mathrm{i}}$ includes all of the factors that affect the decision to enter in sexual activity.

The probability to enter in sexual activity can then be written as follows:

$$
\begin{aligned}
P\left(Y_{i}=1 \mid X_{i}\right) & =P\left(S_{i}^{*}>0\right) \\
& =P\left(Z_{i}^{\prime} \pi+\mu>0\right) \\
& =P\left(\mu<Z_{i}^{\prime} \pi\right) \\
& =\Phi\left(Z_{i}^{\prime} \pi\right)
\end{aligned}
$$

where $\Phi($.$) is the normal distribution.$

HCM accounts for the selection bias (Heckman, 1979) by using a two-step estimator. To access the effect of education on contraception use in the presence of sample selection, this paper follows Wooldridge (2009) to estimate the model in two stages: The first stage predicts the likelihood of an adolescent to be in sexually active using a Probit model and calculate the predicted inverse Mills ratio. The second stage estimates the decision about contraception including the inverse Mills ratio as a predictor in the model. The presence of the selection 
bias is captured by the coefficient $\lambda$ of the inverse of Mills ratio. Typically, if $\lambda$ is statistically equal to zero, then there is no issue of sample selection. In contrary, if $\lambda$ is statistically different from zero, then there is a sample selection issue and the baseline estimates are biased.

\section{Descriptive Statistics}

Table (1) presents the summary of statistics. Two noteworthy features concerning the relationship between education and contraception use appear in these statistics. In one hand, one stunning fact between the two countries is the education gap: In Burkina Faso, the statistics suggest that $57.2 \%$ of adolescents have no education while only $20 \%$ and $22.8 \%$ have reached primary and secondary school respectively. This low literacy rate in the main sample reflects the youth literacy rate for the country, estimated at $21.6 \%$ in 2013 (World Bank, 2014). In contrast, Nigeria presents a much higher level of adolescents' education. In fact, only $6.67 \%$ of adolescents have no education in Nigeria, which represents a huge difference of more than 50 percentage points. For secondary education and higher, the difference is even more stunning.

In fact, Table (1) shows that $81.7 \%$ of adolescents in Nigeria have at least a secondary degree. Compared to Burkina Faso this represents a difference of 58.9 percentage points. Interestingly, the results show that the rate of contraception use is also low among adolescents aged 15-19 in Burkina Faso (26 percent) than in Nigeria (38.4 percent). On the other hand, by carefully considering each country, Figure 2 and Figure 3 reveal a positive association between the level of education and contraception use. In fact, Figure 2 shows that only $10.1 \%$ of adolescents without education use contraception while more than the half $(52.6 \%)$ of adolescents with secondary education use contraception in Burkina Faso. The same feature is observed in Nigeria (Figure 3) where barely $0.7 \%$ of uneducated adolescents use contraception. This rate increased to $35.6 \%$ when the adolescent has a secondary education. Put together, these two features suggest that education is positively correlated with contraception use in both countries.

For other statistics, as far as the exposure to media is concerned, more than the two thirds of adolescents have access to media channels such as radio, TV and/or internet in both countries. The statistics also show that almost a half (48.8\% in Burkina Faso and $48.3 \%$ in Nigeria) have access to information about STIs. The main sample contains $83 \%$ of female adolescents in Burkina Faso and $84.5 \%$ in Nigeria. Statistics also reveal that adolescents in Nigeria enter in sexual activity earlier than those in Burkina Faso. On average, adolescents enter into sexual activity earlier in Nigeria (15.66 years old) than in Burkina Faso (16.3 years old).

Table 1. Descriptive statistics

\begin{tabular}{|c|c|c|c|c|c|c|c|c|c|c|}
\hline \multirow[b]{2}{*}{ VARIABLES } & \multicolumn{5}{|c|}{ Burkina Faso } & \multicolumn{5}{|c|}{ Nigeria } \\
\hline & $\mathrm{N}$ & mean & $\mathrm{sd}$ & $\min$ & $\max$ & $\mathrm{N}$ & mean & $\mathrm{sd}$ & $\min$ & $\max$ \\
\hline Contraception use & 1,410 & 0.260 & 0.439 & 0 & 1 & 1,844 & 0.384 & 0.487 & 0 & 1 \\
\hline \multicolumn{11}{|l|}{ Education level } \\
\hline No education & 1,410 & 0.572 & 0.495 & 0 & 1 & 1,844 & 0.0667 & 0.250 & 0 & 1 \\
\hline Primary & 1,410 & 0.200 & 0.400 & 0 & 1 & 1,844 & 0.117 & 0.321 & 0 & 1 \\
\hline Secondary and more & 1,410 & 0.228 & 0.420 & 0 & 1 & 1,844 & 0.817 & 0.387 & 0 & 1 \\
\hline Information on STI & 1,410 & 0.543 & 0.498 & 0 & 1 & 1,844 & 0.714 & 0.452 & 0 & 1 \\
\hline Female & 1,410 & 0.800 & 0.400 & 0 & 1 & 1,844 & 0.714 & 0.452 & 0 & 1 \\
\hline \multicolumn{11}{|l|}{ Age dummy } \\
\hline 15 years old & 1,410 & 0.0326 & 0.178 & 0 & 1 & 1,844 & 0.0705 & 0.256 & 0 & 1 \\
\hline 16 years old & 1,410 & 0.106 & 0.308 & 0 & 1 & 1,844 & 0.0987 & 0.298 & 0 & 1 \\
\hline 17 years old & 1,410 & 0.199 & 0.400 & 0 & 1 & 1,844 & 0.175 & 0.380 & 0 & 1 \\
\hline 18 years old & 1,410 & 0.307 & 0.461 & 0 & 1 & 1,844 & 0.312 & 0.464 & 0 & 1 \\
\hline 19 years old & 1,410 & 0.355 & 0.479 & 0 & 1 & 1,844 & 0.343 & 0.475 & 0 & 1 \\
\hline Rural resident & 1,410 & 0.621 & 0.485 & 0 & 1 & 1,844 & 0.572 & 0.495 & 0 & 1 \\
\hline Age at first sex & 1,410 & 16.03 & 1.424 & 10 & 19 & 1,844 & 15.66 & 1.860 & 8 & 19 \\
\hline Number of partners & 1,410 & 0.913 & 0.470 & 0 & 7 & 1,844 & 0.893 & 0.449 & 0 & 3 \\
\hline Access to condom & 1,410 & 0.563 & 0.496 & 0 & 1 & 1,844 & 0.553 & 0.497 & 0 & 1 \\
\hline Exposure to Media & 1,410 & 0.842 & 0.365 & 0 & 1 & 1,844 & 0.892 & 0.310 & 0 & 1 \\
\hline
\end{tabular}




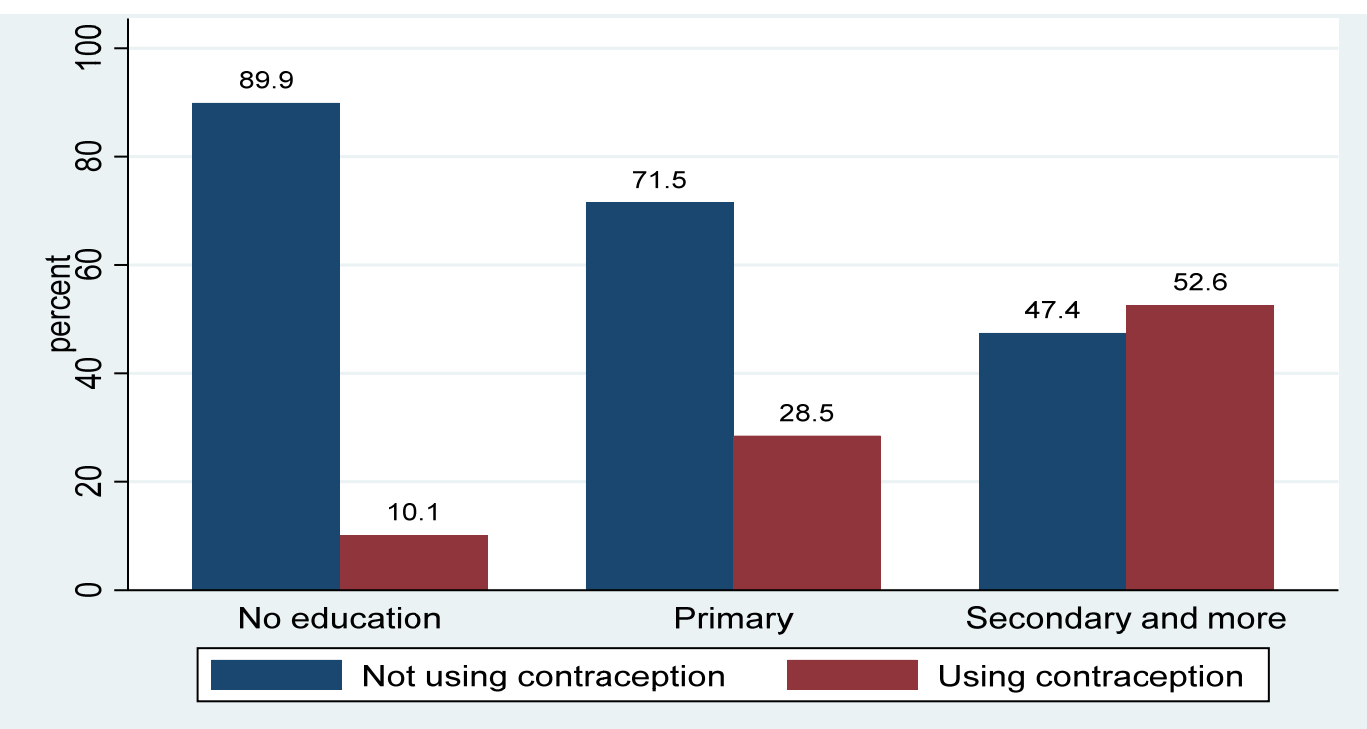

Figure 2. Percentage of adolescents using contraception by level of education in Burkina Faso

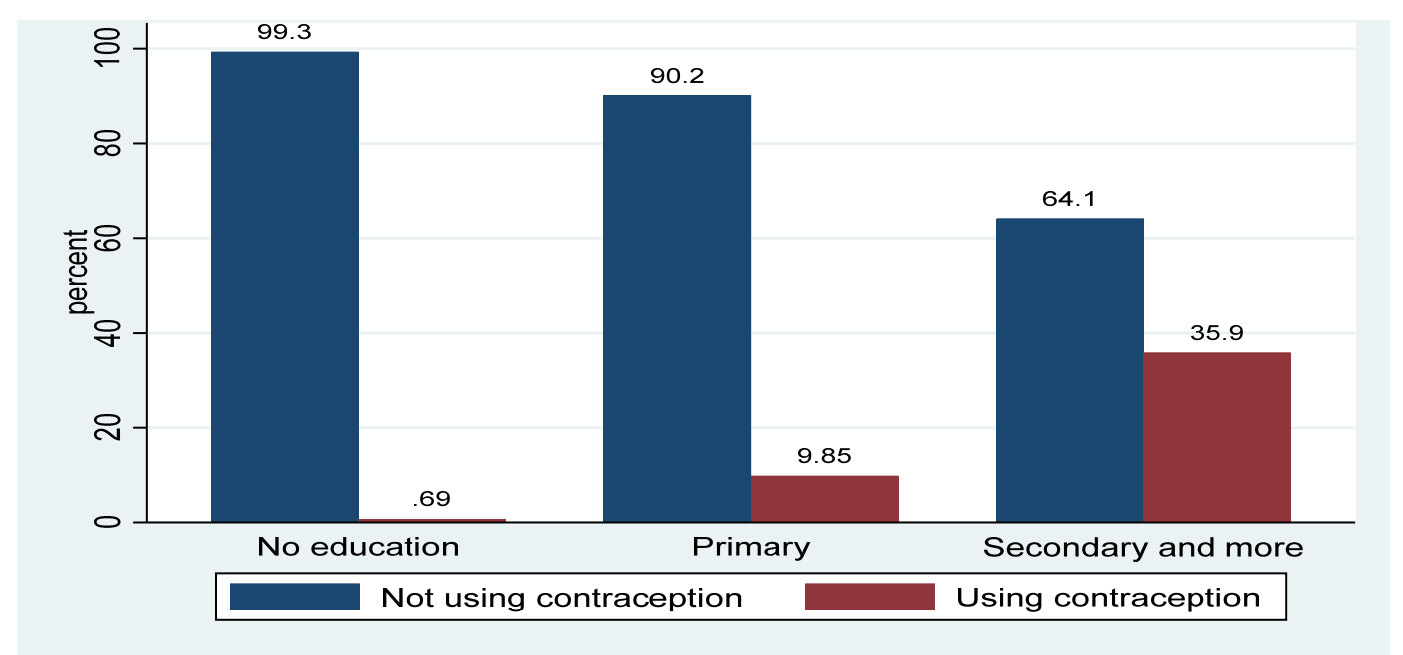

Figure 3. Percentage of adolescents using contraception by level of education in Nigeria

\section{Estimation Results}

\subsection{Probit Estimates}

The Probit estimates of Equation (1) are presented in Table (2). Columns (2) and (4) present the marginal effects from Burkina Faso and Nigeria respectively. In the case of Burkina Faso, the results suggest that having a primary school education increases the probability that an adolescent uses contraception during intercourse by 8.26 percentage points compared to an adolescent without education at all. This effect increases to 20.3 percentage points for adolescents with a secondary school education or more. In the case of Nigeria, the effect of education on contraception use also appears positive and even higher compared to Burkina Faso. In fact, the probability that an adolescent with a primary school education will use contraception is 17.2 percentage points higher than the probability of an adolescent who does not attend school. Moreover, being in secondary school or higher increases the probability that an adolescent will use contraception by 34.7 percentage points. Hence, these results suggest that adolescents' exposure to school education has a positive effect on the probability that they will use contraception. In addition, by controlling for the access to information about STI, the estimates suggest that adolescents who have been provided with information about STI are more likely to use contraception than adolescents who have no information on STIs. In addition, the results suggest that female adolescents have more probability to use contraception in Nigeria. However, females have a lower probability to use contraception in 
Burkina Faso. The model also controls for age and find that contraception use does not depend on an adolescent' age.

Looking at the number of partners, the results suggest that having one additional partners increases the probability that adolescent use contraception by 28.4 percentage points in Burkina Faso and 31.8 percentage points in Nigeria. In fact, these results are consistent with the fact that having several sex partners increases the risk of STIs and hence, the need of protection. For both countries, adolescents who have better access to condoms tends to use more contraception than their counterpart who do not have access to condoms. This result is consistent with the negative effect of living in rural areas in both two countries. The results also suggest that the exposure to media such as radio, TV, boosts awareness creation and thus increases the probability to use contraception methods in Burkina Faso but not in Nigeria. As far as the age at first sex is concerned, the data suggest that adolescents who enter early in sexual activity tend to use more contraception in Nigeria and less in Burkina Faso.

However, these baseline estimates might be biased because of the sample selection since the entry into sexual activity is not random. The HCM is used to correct for this selection bias in order to estimate consistent effects.

Table 2. Standard Probit estimates

\begin{tabular}{|c|c|c|c|c|}
\hline \multirow[t]{2}{*}{ Dependent variable is Contraception use $(0 / 1)$} & \multicolumn{2}{|l|}{ Burkina Faso } & \multicolumn{2}{|l|}{ Nigeria } \\
\hline & $(1)$ & $(2)$ & (3) & (4) \\
\hline VARIABLES & Coefficients & Marginal effects & Coefficients & Marginal effects \\
\hline \multicolumn{5}{|l|}{ Education Base: No education } \\
\hline \multirow[t]{2}{*}{ Primary } & $0.375 * * *$ & $0.0826^{* * *}$ & $0.860 * * *$ & $0.172 * * *$ \\
\hline & $(0.112)$ & $(0.0259)$ & $(0.229)$ & $(0.0379)$ \\
\hline \multirow[t]{2}{*}{ Secondary and more } & $0.822 * * *$ & $0.203 * * *$ & $1.417 * * *$ & $0.347 * * *$ \\
\hline & $(0.118)$ & $(0.0322)$ & $(0.213)$ & $(0.0291)$ \\
\hline \multirow[t]{2}{*}{ Access to information on STI } & $0.323 * * *$ & $0.0693^{* * *}$ & $0.275^{* * *}$ & $0.0867 * * *$ \\
\hline & $(0.0959)$ & $(0.0206)$ & $(0.0731)$ & $(0.0229)$ \\
\hline \multirow[t]{2}{*}{ Female dummy } & $-0.914 * * *$ & $-0.196 * * *$ & $0.199 * *$ & $0.0627 * *$ \\
\hline & $(0.117)$ & $(0.0231)$ & $(0.0829)$ & $(0.0261)$ \\
\hline \multicolumn{5}{|l|}{ Age dummy (Base: 15 years) } \\
\hline \multirow[t]{2}{*}{16 years old } & 0.255 & 0.0497 & -0.0977 & -0.0305 \\
\hline & $(0.276)$ & $(0.0518)$ & $(0.161)$ & $(0.0505)$ \\
\hline \multirow[t]{2}{*}{17 years old } & 0.401 & $0.0813^{*}$ & 0.122 & 0.0391 \\
\hline & $(0.263)$ & $(0.0489)$ & $(0.150)$ & $(0.0476)$ \\
\hline \multirow[t]{2}{*}{18 years old } & 0.225 & 0.0435 & 0.0325 & 0.0103 \\
\hline & $(0.263)$ & $(0.0483)$ & $(0.144)$ & $(0.0456)$ \\
\hline \multirow[t]{2}{*}{19 years old } & 0.393 & 0.0794 & -0.0500 & -0.0157 \\
\hline & $(0.271)$ & $(0.0503)$ & $(0.147)$ & $(0.0462)$ \\
\hline \multirow[t]{2}{*}{ Age at first sex } & $-0.0831 * *$ & $-0.0178 * *$ & $0.0435^{* *}$ & $0.0137 * *$ \\
\hline & $(0.0345)$ & $(0.00737)$ & $(0.0203)$ & $(0.00639)$ \\
\hline \multirow[t]{2}{*}{ Number of partners } & $1.324 * * *$ & $0.284 * * *$ & $1.008 * * *$ & $0.318 * * *$ \\
\hline & $(0.176)$ & $(0.0338)$ & $(0.0947)$ & $(0.0267)$ \\
\hline \multirow[t]{2}{*}{ Access to condom } & $0.460 * * *$ & $0.0987 * * *$ & $0.550 * * *$ & $0.174 * * *$ \\
\hline & $(0.103)$ & $(0.0217)$ & $(0.0734)$ & $(0.0220)$ \\
\hline \multirow[t]{2}{*}{ Exposure to media } & $0.259 *$ & $0.0556^{*}$ & 0.126 & 0.0396 \\
\hline & $(0.151)$ & $(0.0323)$ & $(0.121)$ & $(0.0382)$ \\
\hline \multirow[t]{2}{*}{ Residence area } & $-0.462 * * *$ & $-0.0991 * * *$ & $-0.205 * * *$ & $-0.0647 * * *$ \\
\hline & $(0.0945)$ & $(0.0197)$ & $(0.0665)$ & $(0.0208)$ \\
\hline \multirow[t]{2}{*}{ Constant } & $-0.994 *$ & & $-3.840 * * *$ & \\
\hline & $(0.576)$ & & $(0.405)$ & \\
\hline Observations & 1,402 & 1,402 & 1,829 & 1,829 \\
\hline
\end{tabular}

Note. Robust standard errors in parentheses $* * * \mathrm{p}<0.01, * * \mathrm{p}<0.05, * \mathrm{p}<0.1$. 


\subsection{HCM Estimates}

Table (3) presents the consistent HCM estimates. The statistics of the coefficients $\lambda$ of the Mills ratio of both Burkina Faso and Nigeria are significant. This confirms the presence of selection bias in the baseline estimates and supports the use of HCM as a consistent identification strategy of the effect of education on contraception use. In Burkina Faso, the results suggest that having a primary school education increases the probability of contraception use by 10.5 percentage points which is higher than the baseline estimates in Table (2). The effect of secondary school education estimated by HCM is also 24.4 percentage points higher than the Probit estimates. In Nigeria, having a primary school education increases the probability of using contraception by 15.1 percentage points which smaller than the standard Probit estimates. The estimate from HCM for secondary and higher school is 34 percentage points which is also smaller than the effect estimated in the baseline Probit. To summarize, the study finds that school education has a positive effect on contraception use for both countries. However, the simple Probit estimates underestimate this effect in the case of Burkina Faso and overestimate the effect in the case of Nigeria.

Table 3. HCM estimates

\begin{tabular}{|c|c|c|}
\hline $\begin{array}{l}\text { Dependent variable is } \\
\text { Contraception use }(0 / 1)\end{array}$ & Burkina Faso & Nigeria \\
\hline \multicolumn{3}{|l|}{ Education: Base (No education) } \\
\hline Primary & $\begin{array}{l}0.102 * * * \\
(0.0260)\end{array}$ & $\begin{array}{l}0.151 * * * \\
(0.0500)\end{array}$ \\
\hline Secondary and more & $\begin{array}{l}0.244 * * * \\
(0.0277)\end{array}$ & $\begin{array}{l}0.340 * * * \\
(0.0435)\end{array}$ \\
\hline Female & $\begin{array}{l}-0.287 * * * \\
(0.0272)\end{array}$ & $\begin{array}{l}0.0362 \\
(0.0261)\end{array}$ \\
\hline \multicolumn{3}{|l|}{ Age group (Base $=15$ years old $)$} \\
\hline 16 years old & $\begin{array}{l}0.0769 \\
(0.0607)\end{array}$ & $\begin{array}{l}-0.0519 \\
(0.0505)\end{array}$ \\
\hline 17 years old & $\begin{array}{l}0.103^{*} \\
(0.0582)\end{array}$ & $\begin{array}{l}0.0217 \\
(0.0466)\end{array}$ \\
\hline 18 years old & $\begin{array}{l}0.0621 \\
(0.0578)\end{array}$ & $\begin{array}{l}-0.0116 \\
(0.0450)\end{array}$ \\
\hline 19 years old & $\begin{array}{l}0.0975^{*} \\
(0.0584)\end{array}$ & $\begin{array}{l}-0.0395 \\
(0.0456)\end{array}$ \\
\hline Age at first sex & $\begin{array}{l}-0.0233 * * * \\
(0.00765)\end{array}$ & $\begin{array}{l}0.00632 \\
(0.00634)\end{array}$ \\
\hline Number of sex partners & $\begin{array}{l}0.122 * * * \\
(0.0311)\end{array}$ & $\begin{array}{l}0.162 * * * \\
(0.0435)\end{array}$ \\
\hline Access to condom & $\begin{array}{l}0.0910^{* * *} \\
(0.0221)\end{array}$ & $\begin{array}{l}0.176^{* * *} \\
(0.0232)\end{array}$ \\
\hline Access to information about STI & $\begin{array}{l}0.0730 * * * \\
(0.0207)\end{array}$ & $\begin{array}{l}0.0759 * * * \\
(0.0229)\end{array}$ \\
\hline Exposure to media & $\begin{array}{l}0.0409 \\
(0.0270)\end{array}$ & $\begin{array}{l}0.0362 \\
(0.0352)\end{array}$ \\
\hline Rural resident & $\begin{array}{l}-0.123 * * * \\
(0.0224)\end{array}$ & $\begin{array}{l}-0.0801 * * * \\
(0.0214)\end{array}$ \\
\hline Constant & $\begin{array}{l}0.571 * * * \\
(0.137)\end{array}$ & $\begin{array}{l}-0.266^{* *} \\
(0.129)\end{array}$ \\
\hline \multicolumn{3}{|l|}{ Sexual activity $(0 / 1)$} \\
\hline \multicolumn{3}{|l|}{ Education: Base (No education) } \\
\hline Primary & $\begin{array}{l}-0.125 \\
(0.107)\end{array}$ & $\begin{array}{l}0.659^{* * *} \\
(0.236)\end{array}$ \\
\hline Secondary and more & $\begin{array}{l}-0.547 * * * \\
(0.113)\end{array}$ & $\begin{array}{l}0.474 * * \\
(0.218)\end{array}$ \\
\hline Female & $\begin{array}{l}0.449 * * * \\
(0.0996)\end{array}$ & $\begin{array}{l}0.311 * * * \\
(0.0740)\end{array}$ \\
\hline \multicolumn{3}{|l|}{ Age group (Base $=15$ years old $)$} \\
\hline 16 years old & $\begin{array}{l}0.774 * * * \\
(0.196)\end{array}$ & $\begin{array}{l}0.292 * * \\
(0.115)\end{array}$ \\
\hline 17 years old & $\begin{array}{l}0.993 * * * \\
(0.193)\end{array}$ & $\begin{array}{l}0.460 * * * \\
(0.112)\end{array}$ \\
\hline
\end{tabular}




\begin{tabular}{lll}
\hline 18 years old & $1.521^{* * *}$ & $0.775^{* * *}$ \\
& $(0.192)$ & $(0.105)$ \\
19 years old & $1.904^{* * *}$ & $0.926^{* * *}$ \\
& $(0.191)$ & $(0.111)$ \\
Age at first sex & $0.196^{* *}$ & $0.294^{* * *}$ \\
& $(0.0977)$ & $(0.0733)$ \\
Access to condom & $0.169^{*}$ & $0.244^{* * *}$ \\
& $(0.0894)$ & $(0.0690)$ \\
Access to information about STI & -0.152 & -0.0894 \\
& $(0.114)$ & $(0.120)$ \\
Exposure to media & 0.0851 & $0.190^{* * *}$ \\
& $(0.0966)$ & $(0.0653)$ \\
constant & $-2.740^{* * *}$ & $-2.870^{* * *}$ \\
& $(0.242)$ & $(0.251)$ \\
Mills ratio: lambda & $-0.128^{* * *}$ & $-0.124 * * *$ \\
\hline
\end{tabular}

Note. Robust standard errors in parentheses $* * * \mathrm{p}<0.01, * * \mathrm{p}<0.05, * \mathrm{p}<0.1$.

\section{Discussion: How Does Education Attainment Increase Contraception Use?}

This section focuses on the mechanisms driving the positive relationship between adolescents' education attainment and their contraception use. Four main channels have been identified in the literature to explain the effect of education on contraception use (Gordon, Sabates, Bond, \& Wubshet, 2011; Hogan et al., 1999) (Jejeebhoy, 1995; Rosenzweig \& Schultz, 1989). These channels include (i) knowledge (ii) access to health services (iii) attitudinal factors and (iv) family planning.

Knowledge: In a study in Ethiopia, Gordon et al. (2011) shows that the effect of education on contraception use is mainly mediated by knowledge. First, education leads to a better comprehension of STIs risks and the benefit of contraceptive choices. Secondly, education increases the knowledge of correct contraception method use and the effectiveness of each contraception method. Knowledge increases adolescents' willingness to use contraception (Anochie \& Ikpeme, 2003; Hogan et al., 1999; Rosenzweig \& Schultz, 1989). Finally, Anochie and Ikpeme (2003) finds that education address adolescent's misconceptions about effective methods of contraception, leading them to a better understanding of contraceptive methods. In terms, through the increase of knowledge about sexuality and contraception, education promotes the use of contraception among adolescents.

Access to health services: The second channel through which education increase adolescents' contraception use is the access to health services. In fact, adolescents with a higher education are more likely to visit a doctor or a health professional to seek for information and counseling about sexuality and go on to use contraception (Gordon et al., 2011; Jejeebhoy, 1995).

Attitude toward contraception: (Gordon et al., 2011) shows that education leads to positive attitudes of adolescents about contraception by reducing the fears of a particular method of contraception.

Family Planning: Studies on fertility in developing countries indicate that education increases the need for birth control (DeCicca \& Krashinsky, 2015) and by this way promotes the use of contraception (Ferré, 2009).

\section{Conclusion}

This paper analyses the effect of school education on contraception use among adolescents aged 15-19 in Burkina Faso and Nigeria. Using the Demographic Health Survey of Burkina Faso (2014) and Nigeria (2013), the baseline estimates use Probit regressions to estimate the effect of education on adolescent contraception. As Larsson and Stanfors (2014), the baseline analysis excludes the adolescents who have never engaged in sexual activity. The research findings show that adolescents who achieved a greater level of education have a higher probability to use contraception. However, this method leads to inconsistent estimates since being sexually active is not random.

Subsequently, to access consistent estimates of the effect of education on contraception use, a HCM is applied to account for this selection bias. The findings suggest that education increase contraception use among adolescents in both Burkina Faso and Nigeria. In Burkina Faso, the results suggest that having a primary education increased the probability to use contraception by 10.5 percentage points which is higher than the Probit estimates. The effect of secondary education is also higher 24.4 percentage points than the Probit estimates. In Nigeria, having a primary school education increases the probability of using contraception by 15.1 percentage points which is smaller than the standard Probit estimates. The HCM's estimated effect of secondary and higher education amounted to 34 percentage point which is also smaller than the effect estimated in baseline Probit. 
Several channels such as knowledge, access to health services, attitudinal factors and family planning are advocated to explain the positive relationship between educational attainment and adolescents' probability to use contraception. However, because of the unavailability of data, this study does not focus on sex education particularly but on the exposure to school education in general. It also does not account for quality of education because of missing data on the quality of education in our database. In other words, does the link between education and contraception use depend on the content and the quality of school teaching? An interesting direction for future research will be to examine the relationship between the content and the quality of education and adolescent's contraception use in developing countries.

\section{References}

Ainsworth, M., Beegle, K., \& Nyamete, A. (1996). The impact of women's schooling on fertility and contraceptive use: A study of fourteen sub-Saharan African countries. The World Bank Economic Review, 10(1), 85-122. https://doi.org/10.1093/wber/10.1.85

Alabi, O., \& Oni, I. O. (2017). Teenage Pregnancy in Nigeria: Causes, Effect and Control. International Journal of Academic Research in Business and Social Sciences, 7(2), 17-32. Retrieved from http://hrmars.com/hrmars_papers/Teenage_Pregnancy_in_Nigeria_Causes,_Effect_and_Control.pdf

Anochie, I., \& Ikpeme, E. (2003). The knowledge, attitude and use of contraception among secondary school girls in Port Harcourt. Nigerian journal of medicine: journal of the National Association of Resident Doctors of Nigeria, 12(4), 217-220. Retrieved from http://europepmc.org/abstract/med/14768197

Arcidiacono, P., Khwaja, A., \& Ouyang, L. (2012). Habit persistence and teen sex: Could increased access to contraception have unintended consequences for teen pregnancies? Journal of Business \& Economic Statistics, 30(2), 312-325. https://doi.org/10.1080/07350015.2011.652052

Beekle, A., \& McCabe, C. (2006). Awareness and determinants of family planning practice in Jimma, Ethiopia. International Nursing Review, 53(4), 269-276. https://doi.org/10.1111/j.1466-7657.2006.00492.x

Biddlecom, A. E., Singh, S., \& Munthali, A. (2007). Adolescents' views of and preferences for sexual and reproductive health services in Burkina Faso, Ghana, Malawi and Uganda. African Journal of Reproductive Health, 11(3), 99-110. https://doi.org/10.2307/25549734

Bongaarts, J. (2003). Completing the fertility transition in the developing world: The role of educational differences and fertility preferences. Population Studies, 57(3), 321-335. https://doi.org/10.1080/0032472032000137835

Cannonier, C. (2012). State abstinence education programs and teen birth rates in the US. Review of Economics of the Household, 10(1), 53-75. https://doi.org/10.1007/s11150-011-9131-8

Cleland, J. G., Ndugwa, R. P., \& Zulu, E. M. (2011). Family planning in sub-Saharan Africa: progress or stagnation? Bulletin of the World Health Organization, 89(2), 137-143. Retrieved from https://www.scielosp.org/scielo.php?pid=S0042-96862011000200013\&script=sci_arttext\&tlng=en

DeCicca, P., \& Krashinsky, H. (2015). Does education reduce teen fertility? Evidence from Compulsory Schooling Laws.

Dehne, K. L., Riedner, G., Berer, M., \& Organization, W. H. (2005). Sexually transmitted infections among adolescents: the need for adequate health services. Retrieved from http://apps. who.int/iris/bitstream/handle/10665/43221/9241562889.pdf;jsessionid=27F32DD9DFD23249C 7E79A41EDCEDED3? sequence $=1$

DiCenso, A., Guyatt, G., Willan, A., \& Griffith, L. (2002). Interventions to reduce unintended pregnancies among adolescents: systematic review of randomised controlled trials. Bmj, 324(7351), 1426. https://doi.org/10.1136/bmj.324.7351.1426

Evans, W. N., Oates, W. E., \& Schwab, R. M. (1992). Measuring peer group effects: A study of teenage behavior. Journal of Political Economy, 100(5), 966-991. https://doi.org/10.1086/261848

Ferré, C. (2009). Age at first child: does education delay fertility timing? The case of Kenya. Retrieved from https://papers.ssrn.com/sol3/papers.cfm?abstract_id $=1344718$

Girma, S., \& Paton, D. (2014). Is education the best contraception? the case of declining teenage pregnancy in england. Retrieved from https://papers.ssrn.com/sol3/papers.cfm?abstract_id $=2462432$

Gordon, C., Sabates, R., Bond, R., \& Wubshet, T. (2011). Women's education and modern contraceptive use in Ethiopia. International Journal of Education, 3(1), 1. https://doi.org/10.5296/ije.v3i1.622 
Gronau, R. (1974). Wage comparisons-A selectivity bias. Journal of Political Economy, 82(6), 1119-1143. https://doi.org/10.1086/260267

Heckman, J. J. (1979). Statistical models for discrete panel data: Department of Economics and Graduate School of Business, University of Chicago Chicago, IL.

Hogan, D. P., Berhanu, B., \& Hailemariam, A. (1999). Household organization, women's autonomy, and contraceptive behavior in southern Ethiopia. Studies in family planning, 30(4), 302-314. https://doi.org/10.1111/j.1728-4465.1999.t01-2-.x

Jejeebhoy, S. J. (1995). Women's education, autonomy, and reproductive behaviour: Experience from developing countries. OUP Catalogue. Retrieved from https://ideas.repec.org/b/oxp/obooks/9780198290339.html

Khan, S., Mishra, V., Arnold, F., \& Abderrahim, N. (2007). Contraceptive trends in developing countries. Retrieved from https://www.popline.org/node/199753

Klick, J., \& Stratmann, T. (2008). Do spa visits improve health: evidence from German micro data. Eastern Economic Journal, 34(3), 364-374. https://doi.org/10.1057/palgrave.eej.9050038

Kohler, P. K., Manhart, L. E., \& Lafferty, W. E. (2008). Abstinence-only and comprehensive sex education and the initiation of sexual activity and teen pregnancy. Journal of Adolescent Health, 42(4), 344-351. https://doi.org/10.1016/j.jadohealth.2007.08.026

Korra, A. (2002). Attitudes toward family planning and reasons for nonuse among women with unmet need for family planning in Ethiopia: Citeseer.

Larsson, C., \& Stanfors, M. (2014). Women's education, empowerment, and contraceptive use in sub-Saharan Africa: findings from recent demographic and health surveys. Etude de la Population Africaine, 28(2), 1022. https://doi.org/10.11564/28-0-554

Lewis, H. G. (1974). Comments on selectivity biases in wage comparisons. Journal of Political Economy, 82(6), 1145-1155. https://doi.org/10.1086/260268

Morris, J. L., \& Rushwan, H. (2015). Adolescent sexual and reproductive health: The global challenges. International Journal of Gynecology \& Obstetrics, 131(S1). https://doi.org/10.1016/j.ijgo.2015.02.006

Oettinger, G. S. (1999). The effects of sex education on teen sexual activity and teen pregnancy. Journal of Political Economy, 107(3), 606-644. https://doi.org/10.1086/250073

Rashad, I., \& Kaestner, R. (2004). Teenage sex, drugs and alcohol use: problems identifying the cause of risky behaviors. Journal of health economics, 23(3), 493-503. https://doi.org/10.1016/j.jhealeco.2003.09.009

Rosenzweig, M. R., \& Schultz, T. P. (1989). Schooling, information and nonmarket productivity: contraceptive use and its effectiveness. International Economic Review, 457-477. https://doi.org/10.2307/2526657

Sabia, J. J. (2006). Does sex education affect adolescent sexual behaviors and health? Journal of Policy Analysis and Management, 25(4), 783-802. https://doi.org/10.1002/pam.20208

Santelli, J. S., Lindberg, L., Finer, L. B., \& Singh, S. Recent declines in adolescent pregnancy in the United States: More abstinence or better contraceptive use? Paper presented at the Annual Meeting.

UN. (2016). Global AIDS up date. Retrieved from http://www.who.int/hiv/pub/arv/global-AIDS-update-2016_en.pdf

Winner, B., Peipert, J. F., Zhao, Q., Buckel, C., Madden, T., Allsworth, J. E., \& Secura, G. M. (2012). Effectiveness of long-acting reversible contraception. New England Journal of Medicine, 366(21), 1998-2007. https://doi.org/10.1056/NEJMoa1110855

Wooldridge, M. (2009). An introduction to multiagent systems: John Wiley \& Sons.

World Bank. (2014). Education Statistics, country stats. In: World Bank Group.

World Bank. (2017). Gross Domestic Product per capita, Country profile. In: World Bank Group.

\section{Copyrights}

Copyright for this article is retained by the author, with first publication rights granted to the journal.

This is an open-access article distributed under the terms and conditions of the Creative Commons Attribution license (http://creativecommons.org/licenses/by/4.0/). 